\title{
PEQULIARITIES OF MORPHOGENESYS AND TOPOGRAPHY OF INFRAHYOID TRIANGLES IN HUMAN PREFETUSES AND FETUSES
}

10.36740/WLek202101120

\author{
Olexandr V. Tsyhykalo' ${ }^{1}$, Iryna S. Popova², Olga Ya. Skrynchuk ${ }^{3}$, Tetiana D. Dutka-Svarychevska ${ }^{4}$, Larysa Ya. Fedoniuk ${ }^{5}$ \\ 'DEPARTMENT OF HISTOLOGY, CYTOLOGY AND EMBRYOLOGY, BUKOVINIAN STATE MEDICAL UNIVERSITY, CHERNIVTSI, UKRAINE \\ 2DEPARTMENT OF HISTOLOGY, CYTOLOGY AND EMBRYOLOGY, BUKOVINIAN STATE MEDICAL UNIVERSITY, CHERNIVTSI, UKRAINE \\ ${ }^{3}$ DEPARTMENT OF PHARMACY, BUKOVINIAN STATE MEDICAL UNIVERSITY, CHERNIVTSI, UKRAINE \\ ${ }^{4}$ DEPARTMENT OF HISTOLOGY, CYTOLOGY AND EMBRYOLOGY, BUKOVINIAN STATE MEDICAL UNIVERSITY, CHERNIVTSI, UKRAINE \\ ${ }^{5}$ MEDICAL BIOLOGY DEPARTMENT OF THE I. HORBACHEVSKY STATE MEDICAL UNIVERSITY, TERNOPIL, UKRAINE
}

\begin{abstract}
The aim: To investigate morphology and developmental features of anatomical structures in the infrahyoid triangles of human neck during prefetal and fetal periods of human ontogenesis.

Materials and methods: We have studied 30 specimens of human prefetuses from $7^{\text {th }}$ till $12^{\text {th }}$ week $(16,0-82,0 \mathrm{~mm}$ of parieto-coccygeal length (PCL)) and 30 human fetuses aged from $4^{\text {th }}$ till $10^{\text {th }}$ month $(84,0-360,0 \mathrm{~mm} \mathrm{PCL})$ of intrauterine development by the means of macro-, microscopy, morphometry, three-dimensional remodeling and statistical analyses. Results: We can observe anterior triangle in human fetuses after the time when common precursor muscular mass splits into two: the anterior and posterior portions which will give rise to the sternocleidomastoid and trapezoid muscles accordingly. The area index of the central triangle in human fetuses $4^{\text {th }}-10^{\text {th }}$ month of intrauterine development shows the increasing tendency with the highest rates at $8^{\text {th }}-10^{\text {th }}$ months period $-1100-1200 \mathrm{~mm}^{2}$. The angulated course of omohyoid muscle is visible at late prefetal and early fetal periods $\left(3-4^{\text {th }}\right.$ month; $\left.80,0-130,0 \mathrm{PCL}\right)$ as well as the presence of intermediate tendon. Peaks of the area of sternocleidomastoid region area evaluation was observed in $190,0-210,0 \mathrm{~mm}$ PCL and $260,0-270,0 \mathrm{~mm}$ PCL human fetuses; $6^{\text {th }}$ and $7,5^{\text {th }}$ months accordingly.

Conclusions: The critical periods for the AT and SCM regions should be considered $6^{\text {th }}$ and $8^{\text {th }}$ months of the IUD. Prefetal period shows the presence of AT and border structure for the IH neck - precursor of HB. Fetal period of IUD ( $4^{\text {th }}-10^{\text {th }}$ months of IUD) should be considered as such that represents an adult-alike morphology of IH neck: presence of IH triangles with fully developed vascular, muscular and fascial content.
\end{abstract}

KEY WORDS: human prenatal development, neck of human fetus, infrahyoid region, neck morphogenesis

\section{INTRODUCTION}

The spaces that are found in the infrahyoid region are the clinical landmarks for possible spreading diseases of inflammatory (reactive adenopathy or the soft tissues inflammation), odontogenic, traumatic or oncological origins $[1,2,3]$. For instance, these may be oncological metastases (squamous carcinoma of larynx, lymphoma, thyroid cancer), Zenker's diverticulum, thyroglossal duct cyst etc. $[4,5]$. Moreover, braches of nerve supply such as recurrent laryngeal nerve may be often damaged during thyroid surgeries [6]. One of the most common severe complications in the deep infrahyoid region is septic thrombosis of the internal jugular vein (IJV) [2]. Infrahyoid region of neck is also found to tend in high frequency of congenital malformations like thyroglossal duct cyst, lymphangiomas and branchial cleft cysts $[3,7]$. Because all congenital malformations are formed from embryological tissue, knowledge on normal morhogenesis will allow to understand better possible ways of their formation and further effective treatment.
Infrahyoid muscles are used in surgery as flaps for reconstruction procedures of the larynx, esophagus and tongue [8]; laryngopharyngeal reconstruction in patients with pyriform sinus carcinoma [5]. The infrahyoid myocutaneous flap, fed by the superior thyroid artery and with double venous drainage, is used as a reliable and convenient technique for over 40 years $[9,10]$ by surgeons with different modified methods of incisions and flap preservation. We believe that detailed studies of the infrahyoid region in the focus of human prenatal development may help to improve surgical techniques of reconstructive surgeries in children and develop additional prenatal diagnostic indexes for possible congenital malformations detection.

\section{THE AIM}

To investigate and circumscribe morphology, topography and developmental changes of anatomical structures in the infrahyoid triangles of human neck during prenatal period of human development and provide morphometrical data of those. 


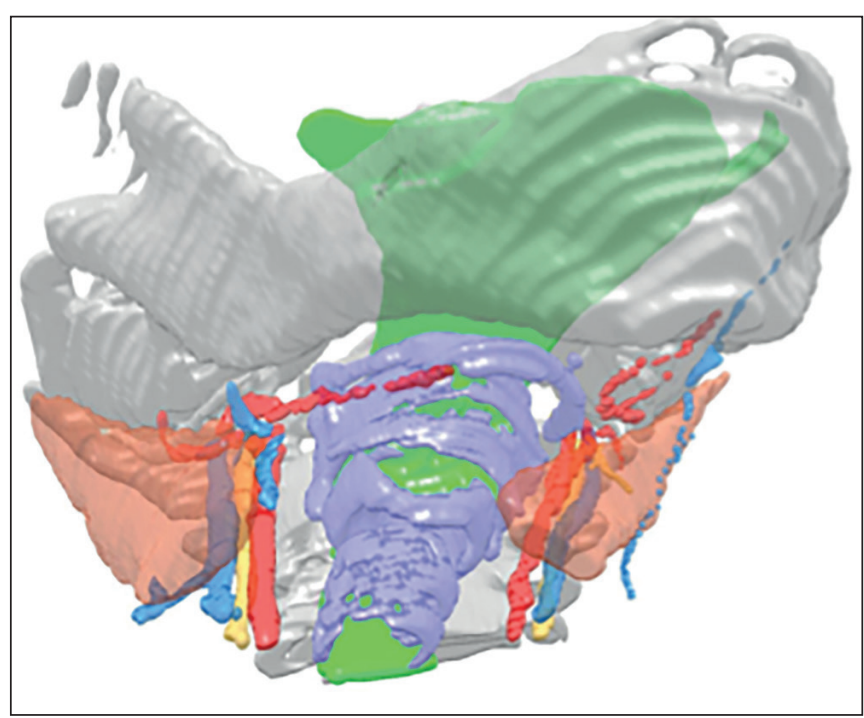

Fig. 1.3D reconstruction of anatomical structures of the anterior triangle of neck of human prefetal specimen $55,0 \mathrm{~mm} \mathrm{PCL}$ (10th week). Antero-inferior view. Magn.:x12:1 - mandible; 2 - sternocleidomastoid muscle; 3 - hyoid bone; 4 - main vasculo-nervous bundle of the neck; 4.1 - common carotid artery; 4.2 - internal jugular vein; 4.3 - vagus nerve; 5 - trachea; 6 thyroid cartilage; 7 - esophagus; 8 - vertebrae; 9 - external jugular vein.

\section{MATERIALS AND METHODS}

The study was performed in accordance with the provisions of the declaration of Helsinki (1995) as revised in Edinburgh (2000), ICH GCP (1996) and had been approved by the Bukovinian State Medical University Ethics Committee. Study is a part of complex scientific work of the Department of Histology, Cytology and Embryology "Regularities of morphogenesis and structural features of tissues and organs in human ontogenesis" (registration number 0116U002938).

Specimens of the fetuses (of both genders) from the Chernivtsy Regional Pathologists Office had been used for research in accordance to bilateral contract on scientific collaboration with the Department of Histology, Cytology and Embryology.

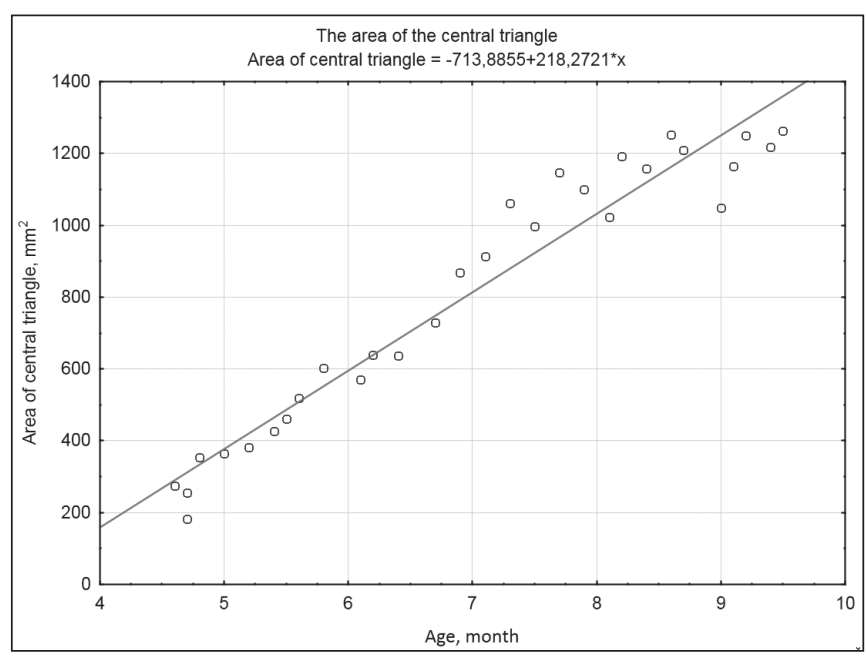

Fig. 3. The area of the central triangle in human fetuses 4 th -10 th month of intrauterine development $(85,0-360,0 \mathrm{~mm} \mathrm{PCL})$.

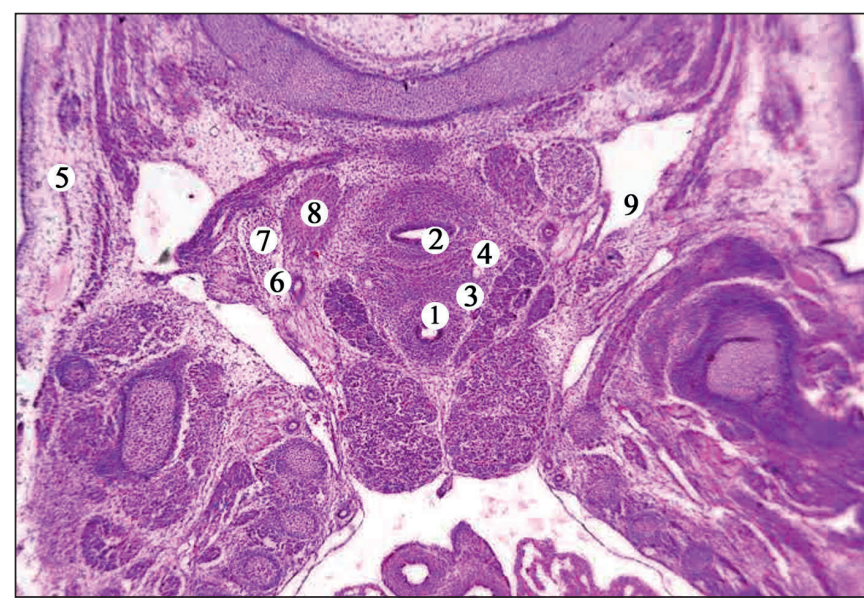

Fig. 2. Frontal section of the neck organs in the human prefetus $30,0 \mathrm{~mm} P C L$. Stained with H\&E.Magn.: X30:1 -trachea;2-0esophagus; 3 -retropharyngeal space; 4 - recurrent laryngeal nerve; 5 - platysma; 6 - common carotid artery; 7 - sternocleidomastoid; 8 - sternothyroid; 9 - omohyoid.

The specimens of human prefetuses aged from $7^{\text {th }}$ till $12^{\text {th }}$ week (16,0-82,0 mm of parieto-coccygeal length ((PCL) and human fetuses aged from $4^{\text {th }}$ till $10^{\text {th }}$ month $(84,0-360,0 \mathrm{~mm}$ PCL$)$ of intrauterine development (IUD) were investigated by means of morphological methods (macroscopy for fetuses, microscopy for prefetuses (with fixation, embedding in dense material, staining with haematolixil \& eosin), 3D-reconstruction for prefetuses (based on series of histological labeled slides, $n= \pm$ 50 from each prefetus specimen), morphometry and statistical analyses). All specimens were obtained from ectopic pregnancies or spontaneous abortions, and no part of the material gave

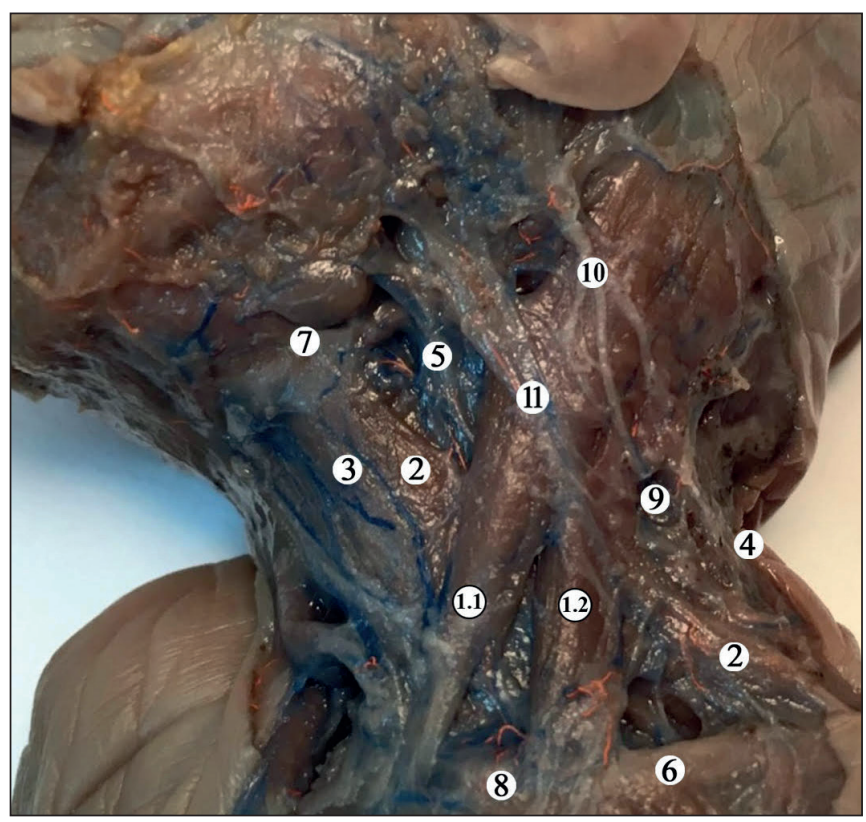

Fig.4. Borders of infrahyoid triangles. Macrospecimen of male human fetus 150,0 mm PCL, left view. Magn.: x2: 1 - sternocleidomastoid muscle and region: 1.1 - sternal head, 1.2 - clavicular head; 2 - omohyoid muscle; 3 - sternohyoid muscle; 4 - trapezius muscle; 5 - braches of v. jugularis interna; 6 - clavicle; 7 - hyoid bone; 8 - supraclavicular nerve twigs; 9 twigs of cervical plexus. 


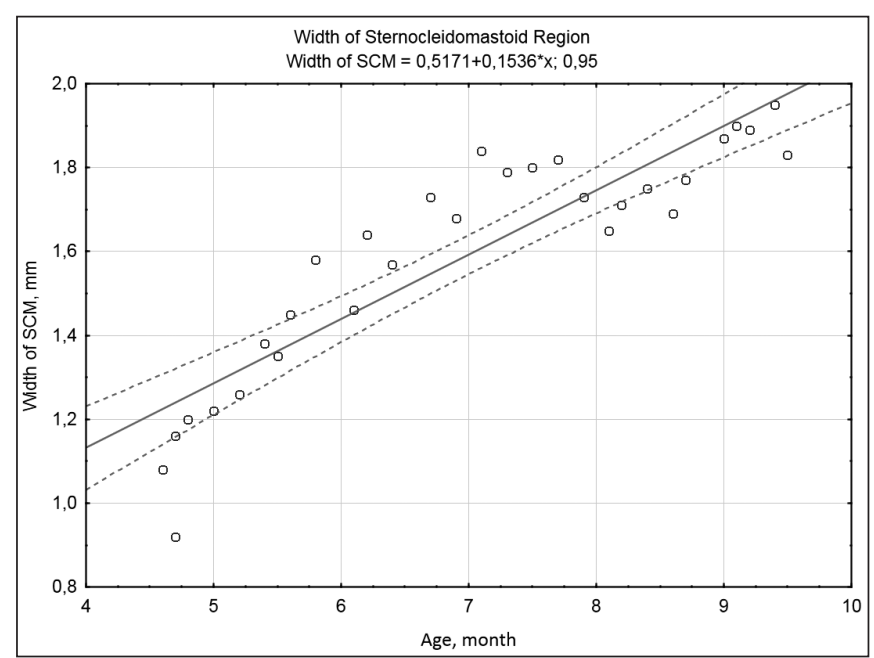

Fig. 5. The width of sternocleidomastoid region in human fetuses 4 th-10th month of intrauterine development $(85,0-360,0 \mathrm{~mm} \mathrm{PCL})$.

indications of possible malformation. Series of histological specimens (embedded in paraffin and stained with haematoxilin and eosin) from prefetal material were conducted by microtome in sagittal and horizontal axes with photographing. Micro- and macroscopy, morphometry was conducted under the control of binocular microscope.

\section{RESULTS AND DISCUSSION}

We have observed that the infrahyoid portion of the neck is represented by triangular areas that are found in space between the hyoid bone $(\mathrm{HB})$ downwards to thoracic inlet starting from $55,0-60,0 \mathrm{~mm}$ PCL prefetuses and later on in the fetal period of the IUD. IH region (including infrahyoid triangles) are seen on three-dimensional reconstructions in middle-aged human prefetuses $(35,0-65,0 \mathrm{~mm}$ PCL) by the means of outlined IH group of muscles, main vascular structures and by the main landmark for delimiting infrahyoid region - the HB (Fig. 1). Three-dimensional reconstruction is believed to be a reliable method for early human development studies $[11,12]$ and we have used it to investigate topographical peculiarities in human fetus o f10th week developmet.

With the help of histological investigation of prefetal material and macroscopic studies of fetal specimens, we have seen that spaces in the infrahyoid region are divided by the means of the deep cervical fascia leaves. Visceral, carotid and the perivertebral spaces are seen much clear comparing to retropharyngeal and posterior cervical in the prefetal period $(30,0-80,0 \mathrm{~mm}$ $\mathrm{PCL}$ ). The superficial covering for infrahyoid neck is skin, superficial neck fascia and platysma. Platysma is represented by a broad thin line of muscular fibers going in one direction, placed immediately beneath the hypodermis. Platysma in fetuses originates from the clavicle and acromion and has oblique direction of fibers towards its insertion to the mandible near the external oblique line; in prefetuses it has shown bigger content of fibrous component comparing to those in fetuses.

We can observe anterior triangle in human fetuses after the time when common precursor muscular mass splits into two:

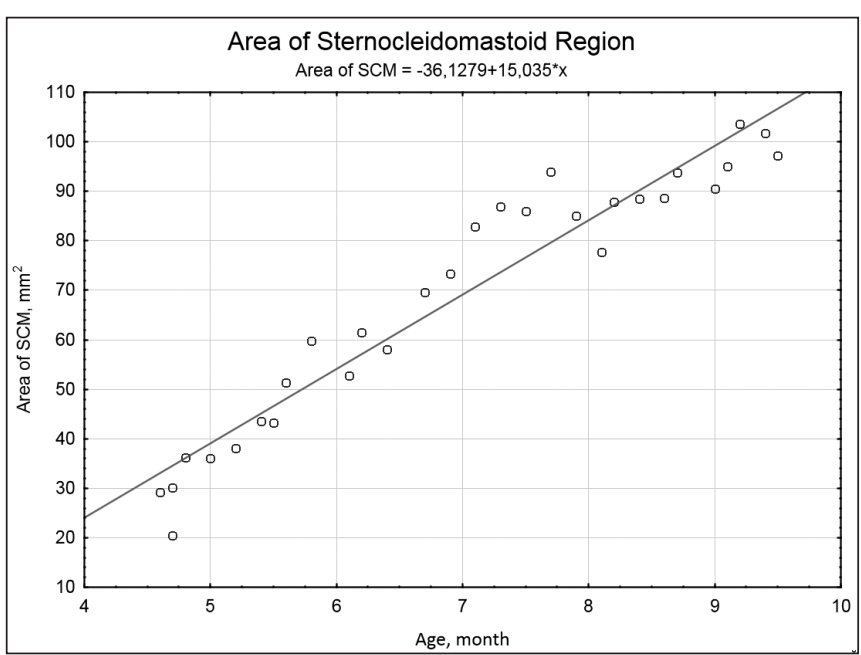

Fig. 6. The area of sternocleidomastoid region in human fetuses 4 th-10th month of intrauterine development $(85,0-360,0 \mathrm{~mm} \mathrm{PCL})$.

the anterior and posterior portions which will give rise to the sternocleidomastoid (SCM) and trapezoid muscles accordingly (Fig. 2). This period is important as a possible time for congenital malformations development $[13,14]$.

This histological picture may be found starting from the middle prefetal period (40,0 mm PCL specimens and on), when SCM has enlarged to the definitive shape and is fixed at its anatomical attachment points (mastoid process in superior portion and the clavicle in the inferior portion of the neck). As a result of this split we can observe boundaries of the anterior triangles in human neck and those lined above by the precursor of $\mathrm{HB}$ will be the infrahyoid ones: carotid, omotracheal, omoclavicular, omotrapezoid and SCM region, that are often used in reconstructive surgeries [8,9]. The mandible superiorly, anterior borders of SCM laterally and the midline of neck are the margins for the AT, covered by the superficial layer of the deep neck fascia and supported deeply by the visceral layer of the deep neck fascia. Multilayered configuration of the neck can be seen starting from 90,0 mm PCL in fetal period, as we have seen that deep cervical fascia has developed its subdivisions: superficial, visceral and deep layers. Fascial layers create fascial spaces, that can be distinguished macroscopically starting from early stages of fetal period (85,0-100,0 mm PCL and on) as they develop some volume of the fatty tissue inside and later on can be classified using an estimated topographical classification [15].

The area of AT is important index for us as it generalizes the content volume of the strap-like infrahyoid muscles: omohyoid $(\mathrm{OH})$, sternohyoid (SH), thyrohyoid, sternothyroid (ST). Blood supply of $\mathrm{IH}$ muscles in fetal period ( $\left(7^{\text {th }}-10^{\text {th }}\right.$ months) is supported by superior and inferior thyroid arteries. The area index $\left(\mathrm{mm}^{2}\right)$ of the central triangle $\left(-713,8855+218,2721^{\star} \mathrm{x}\right)$ in human fetuses $4^{\text {th }}-10^{\text {th }}$ month of IUD $(85,0-360,0 \mathrm{~mm}$ PCL) shows the increasing tendency during IUD with the highest rates at $8^{\text {th }}-10^{\text {th }}$ months period $-1100-1200 \mathrm{~mm}^{2}$ (Fig. 3).

Moreover, Figure 3 shows the general dependence of fetal age (in month of IUD) to the area of anterior triangle and we may deduce the deviations of indexes during each month which shows high rate of individual anatomical distinctions. Even 
though this area index reaches its peak point around 8,5-9 th months of IUD, the critical period of its morphogenesis should be considered $7^{\text {th }}$ month of IUD. This can be explained by the highest intensity of bony structures development (mandible, clavicle, sternum) as well as the critical period for muscular, vascular and fascial structures IUD modification.

Muscular triangle (MT) is lined anteriorly by the midline of neck from the HB to the sternum; posteriorlyby anterior border of SCM; apically by superior belly of $\mathrm{OH}$ muscle. At middle of prefetal stage ( $3^{\text {rd }}$ month of IUD; 54,0-80,0 PCL) OH muscle is found to be innervated from the twigs on ansa cervicalis (AC) and seen as a straight long muscle without intermediate tendon. The angulated course of $\mathrm{OH}$ is visible at late prefetal and early fetal periods ( $3-4^{\text {th }}$ month; 80,0-130,0 PCL) as well as the presence of intermediate tendon. $\mathrm{OH}$ anterior belly arises behind the SCM as a continuation of the posterior belly, ascending almost vertically in close topographical relation to SH muscle (Fig. 4) and attaches to the lower part of HB, that correlates with anatomical studies on $\mathrm{OH}$ morphology $[16,17]$.

The roof of MT is represented by skin, superficial fascia, thin platysma (innervated by superficial braches of the cervical plexus) and leaf of deep neck fascia. Floor of MT is represented by SH and ST muscles. SH and ST are found to be covered by deep layer of the deep neck fascia that is seen as thick layer of dense connective tissue, attached to the posterior border of the HB. In late fetal period (230,0-350,0 PCL; $7-9^{\text {th }}$ month of IUD) the space between two layers of the deep cervical fascia was found to contain moderate amount of adipose tissue. MT contains common carotid artery (CCA), IJV and vagus nerve that lies between the vessels (Fig.4).

SCM runs obliquely across each sides of the neck and is covered by two layers of deep cervical fascia. Prefetuses 55,080,0 PCL already show the presence of two heads in the place of SCM attachment to the sternum and clavicle (Fig.4). Sternal head of SCM starts as a tendon at upper anterior portion of the sternum, that goes upwards as a dense muscle fiber turning backwards obliquely. Clavicular head of SCM is attached to the inner $1 / 3$ posterior border of clavicle as a compact muscle fiber directed vertically upwards. The space between the arising heads of the SCM varies in its triangular shape and size depending on the total lengths of the SCM and its width. Both heads fuse together to form a SCM at the level of $\mathrm{HB}$ and attach to the mastoid process. The width of SCM region (Fig. 5) has evaluated gradually during fetal period (width of SCM = $\left.0,5171+0,1536^{\star} x ; 0,95\right)$ that may be used while studying peal force capabilities of the SCM [18].

Critical periods of its formation may be considered $6^{\text {th }}$ and $7^{\text {th }}$ months of IUD (190,0-260,0 mm PCL). Deviations of indicators from Fig. 5 can prove the variety of morphological course of the SCM development: width can predict the area index and the morphological features of topographical neighboring structures in the IH neck of the future newborn. Deviations of abovementioned index 9if measured prenatally) can be predictor for abnormal course of the SCM morphogenesis (wryneck, development of additional heads etc. [18]).

Area index of the SCM region (Fig. 6) that was analyzed statistically (area of $S C M=-36,1279+15,035^{\star} x$ ), shows that the highest parameter can be found at the $9^{\text {th }}$ month of IUD. This index varies and each IUD period, but also tends to increase gradually. We have observed the highest rate (peaks of evaluation) in 190,0-210,0 mm PCL and 260,0-270,0 mm PCL human fetuses, $6^{\text {th }}$ and $7,5^{\text {th }}$ months accordingly (Fig. 6).

Area index of SCM that we have measured can be used clinically for the prenatal diagnostic, as the SCM region itself holds part of CCA, IJV and vagus nerve. IH portion of SCM in fetal period is supplied by branch of superior thyroid artery.

SCM is the posterior border for the carotid triangle, that contains upper part of CCA and is a place of its bifurcation on external (ECA) and internal carotid arteries (ICA); hypoglossal nerve and the accessory nerve. In the medial portion of ECA, close to $\mathrm{HB}$ we have seen internal branch of superior laryngeal nerve. The inferior border for carotid triangle is the superior belly of the omohyoid; superior border is held by stylohyoid and posterior belly of the digastricus. Roof in carotid triangle is represented by skin, superficial fascia, platysma, investing layer of the deep cervical fascia. CCA runs cranially and complements neurovascular bundle of the neck. Human prefetuses $(82,0$ $\mathrm{mm}$ of PCL) show the presence of fascial coverings (sheath) of the carotid space that are formed as prolongations of the deep cervical fascia covering. We have found fibrous septs between each of the blood vessel within cervical vascular trunk which were included in one common covering. On the right plate of the infrahyoid region of prefetal neck (70,0-82,0 mm PCL), right CCA lies between trachea and anterior scalene muscles. AClies in the anterior wall of carotid layer which is overlapped by anterior edge of SCM. Terminal branches of AC in prefetal and fetal periods show the variety of topographical anastomoses that supply innervation of the infrahyoid muscles [19]. Behind the carotid vessels we may dissect prevertebral fascia that participates in creation of carotid sheath. In front of the carotid vessels next to investing layer of neck fascia we may see pretracheal fascia that continues to the HB.

We haven't found any signs of branchial structures residuals at the prefetal stage $(20,0-80,0 \mathrm{~mm}$ of PCL) that is why no possible congenital abnormalities were observed. We also have not found the residuals of thyroglossal duct at this stage within the strap muscles which means that at prefetal stage tissue of thyroid lobules has isolated from pharyngeal precursor. The thyroid cartilages (cricoid, thyroid and arytenoids) are fully developed in prefetuses 67,0-80,0 mm PCL and finishes the ventral fusion in early fetal period $(96,0 \mathrm{~mm}$ PCL). Two laminae of the thyroid are formed and we may see ventral fusion also.

The vertebral vein is found to descend above the foramen magnum following the course of the posterior jugular vein in prefetuses. It runs above the vertebral artery and descends vertically in the canal of the transverse process of cervical vertebrae next to the artery. Running above the subclavian artery it ends in a trunk to subclavian jugular confluence. The vertebral vein drains venous blood from the deep structures of the $\mathrm{IH}$ region and deep cervical veins. Posterior jugular vein is found to be connected with IJV and vertebral veins. IJV together with subclavian veins create jugular venous angle, which may be considered as the content of lateral triangle of neck and should be carefully operated while conducting neck infection surgeries [2], especially in cases of additional infrahyoid muscles presence [20]. 


\section{CONCLUSIONS}

1. Prefetal period of human ontogenesis is characterized by intensive processes of organogenesis and formation of infrahyoid neck triangles with district borders and content.

2. Fetal period of prenatal development $\left(4^{\text {th }}-10^{\text {th }}\right.$ months of IUD) shows definite morphology of infrahyoid neck that is close to an adult one: muscular, carotid and SCM regions are differentiated with fully developed vascular, muscular and fascial content.

3. Morphometrical indexes of IH neck rely on topographically close structures. The critical periods for the AT and SCM regions should be considered $6^{\text {th }}$ and $8^{\text {th }}$ months of the IUD. Provided morphometric data may be used as some prenatal diagnostic criteria for human fetuses of last trimester.

\section{REFERENCES}

1. Yuan H., Gao R. Infrahyoid involvement may be a high-risk factor in the management of non-odontogenic deep neck infection: Retrospective study. American journal of otolaryngology. 2018;39(4), 373-377.

2. Zhang W., Qian W., Shi H., Zhang W., Chen, M., et al. Internal Jugular Vein Thrombosis with Serious Cervical Necrotizing Fasciitis. Journal of Craniofacial Surgery. 2019;30(6), e487-e489.

3. Kikuta S., Iwanaga J., Kusukawa J., Tubb R.S. Triangles of the neck: a review with clinical/surgical applications. Anatomy \& Cell Biology. 2019;52(2):120-127.

4. Godovanets 0.I., KitsakT.S., Vitkovsky 0.0., Kuzniak L.V., Godovanets 0.S., Chaikovska N.M., Fedoniuk L.Ya. The Influence of Diffuse Nontoxic Goiter on the State of Protective Mechanisms of the Oral Cavity in Children. Journal of Medicine and Life. 2020;13(1):21-25.

5. Anderson D., Selby L.V., Albuja-Cruz M. Papillary Thyroid Carcinoma Arising within a Thyroglossal Duct Cyst. The American Surgeon. 2020;86(3):E139-E141.

6. Anuwong A., Lavazz M., Kim, H.Y., Wu C.W., Rausei S., et al. Recurrent laryngeal nerve management in thyroid surgery: consequences of routine visualization, application of intermittent, standardized and continuous nerve monitoring. Updates in surgery. 2016;68(4):331-341.

7. Ross J., Manteghi A., Rethy K., Ding J., Chennupati S.K. Thyroglossal duct cyst surgery: A ten-year single institution experience. International Journal of Pediatric Otorhinolaryngology. 2017;101:132-136.

8. Yan D., Zhang J., Min X. Modified Infrahyoid Myocutaneous Flap for Laryngopharyngeal Reconstruction. Ear, Nose \& Throat Journal. 2020; 99(1):15-21.

9. Peng H., Wang S.J., Yang X., Guo H., Liu M. Infrahyoid myocutaneous flap for medium-sized head and neck defects: surgical outcome and technique modification. Otolaryngology-Head and Neck Surgery. 2013;148(1):47-53.

10. Nocon C.C., Cohen, M.A., Langerman, A.J. Quality of neck dissection operative reports. American journal of otolaryngology. 2016;37(4):330-333.

11. Belle M., Godefroy D., Couly G., Malone S.A., Collier F., et al. Tridimensional visualization and analysis of early human development. Cell. 2017;169(1):161-173.

12. Saito A., Kishimoto M., Kasahara K., Tsujikawa M., Takakuwa T., et al. Spatiotemporal statistical models of a human embryo. In International Forum on Medical Imaging in Asia 2019. International Society for Optics and Photonics. 2019;11050:110501G.
13. Rodríguez Vázquez J.F., Verdugo López S., Abe H., Murakami G. The origin of the variations of the hyoid apparatus in human. The Anatomical Record. 2015;298(8):1395-1407.

14. Nicollas R., GuelfucciB., RomanS., Triglia J.M. Congenital cysts and fistulas of the neck. International Journal of Pediatric Otorhinolaryngology. 2000;55(2):117-124.

15. Suman S., Topor B., Suman A. Proiority in classification of cervical fasciae. The Moldovan Medical Journal. 2018;60(4):46-49.

16. Uzun L., Kokten N., Acar, G. O. Trapezoid shaped omohyoideus muscle: An Anatomic Variation seen in Functional Neck Dissection. Otolaryngology online journal. 2015;5(4):139-143.

17. Bhat N., Pandey A. K., Kotian S. R., Kalthur S.G. Omohyoid Muscle: An Anatomical Study. Journal of Krishna Institute of Medical Sciences. 2018;7(3):21-26.

18. Kennedy E., Albert M., Nicholson H. The fascicular anatomy and peak force capabilities of the sternocleidomastoid muscle. Surgical and Radiologic Anatomy. 2017;39(6):629-645.

19. Som P.M., Laitman J.T. Embryology, variations, and innervations of the human neck muscles. Neurographics. 2017;7(3):215-242.

20. Murugan M. S., Sudha R., Bhargavan R. Clinical significance of an unusual variation: Anomalous additional belly of the sternothyroid muscle. Sultan Qaboos University Medical Journal. 2016;16(4): e491.

The work is a fragment of scientific research work of the Department of Histology, Cytology and Embryology of Bukovinian State Medical University "Regularities of morphogenesis and structural features of tissues and organs during human ontogenesis" (registration number 0116U002938).

\section{ORCID and contributionship:}

Olexandr V. Tsyhykalo: 0000-0003-2302-426X ${ }^{A, B, D}$

Iryna S. Popova: 0000-0003-1234-3855 A,B,D

Olga Ya. Skrynchuk: 0000-0001-6498-3497 C,E

Tetiana D. Dutka-Svarychevska: 0000-0003-0356-1666 ${ }^{C, D}$

Larysa Ya. Fedoniuk: 0000-0003-4910-6888 E,F

\section{Conflict of interest:}

The Authors declare no conflict of interest.

\section{CORRESPONDING AUTHOR}

\section{Iryna S. Popova}

Department of Histology, Cytology and Embryology

Bukovinian State Medical University

Kobylianska Street, 42, 58002, Chernivtsy, Ukraine

tel: +380507138313

e-mail:popova_i@bsmu.edu.ua

Received: 09.08.2020

Accepted: 28.12 .2020

A - Work concept and design, B - Data collection and analysis, C - Responsibility for statistical analysis,

D-Writing the article, $\mathbf{E}$-Critical review, $\mathbf{F}$ - Final approval of the article 